\title{
Extension of Tosèla cheese shelf-life using non-starter lactic acid bacteria
}

\author{
Luca Settanni $^{\text {a }}$, Elena Franciosi ${ }^{\text {b,* }}$, Agostino Cavazza ${ }^{\text {, }}$, Pier Sandro Cocconcelli ${ }^{c}$, Elisa Poznanski ${ }^{\text {b, } 1}$ \\ a SENFIMIZO Department, Section of Phytopathology and Agricultural Microbiology, University of Palermo, Viale delle Scienze 4, 90128 Palermo, Italy \\ ${ }^{\mathrm{b}}$ IASMA Research and Innovation Centre, Fondazione Edmund Mach, Food Quality and Nutrition Area, Innovative Food Technologies, Via E. Mach 1, \\ 38010 San Michele all'Adige (TN), Italy

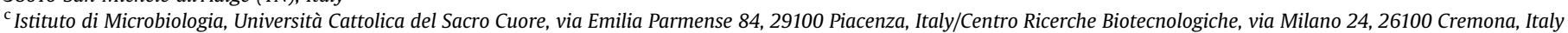

\section{A R T I C L E I N F O}

\section{Article history:}

Received 2 July 2010

Received in revised form

12 November 2010

Accepted 6 December 2010

Available online 13 December 2010

Keywords:

NSLAB

Fresh cheese

Bacteriocins

Shelf-life

\begin{abstract}
A B S T R A C T
Six strains of non-starter lactic acid bacteria (NSLAB) were used to extend the shelf-life of the fresh cheese Tosèla manufactured with pasteurised cows' milk. The acidification kinetics of three Lactobacillus paracasei, one Lactobacillus rhamnosus and two Streptococcus macedonicus were studied in synthetic milk medium. Lb. paracasei NdP78 and NdP88 and S. macedonicus NdP1 and PB14-1 showed an interesting acidifying capacity and were further characterised for growth in UHT milk and production of antimicrobial compounds. Lb. paracasei NdP78 and S. macedonicus NdP1 grew more than 2 log cycles in 6 h. Lb. paracasei NdP78 was also found to produce a bacteriocin-like inhibitory substance (BLIS) active against Listeria monocytogenes. The four NSLAB strains (singly or in combination) were used to produce experimental pilotscale cheeses which were compared by a panel. The cheese manufactured with the mixed culture $L b$. paracasei NdP78 - S. macedonicus NdP1 was the most appreciated for its sensory properties. The cheeses produced at factory-scale showed higher concentrations of lactobacilli (7.90 log CFU/g) and streptococci (6.10 $\log$ CFU/g), but a lower development of coliforms (3.10 log CFU/g) and staphylococci (2.78 log CFU/g) than control cheese $(4.86,4.89,4.93$ and $5.00 \mathrm{log}$ CFU/g of lactobacilli, streptococci, coliforms and staphylococci, respectively) processed without NSLAB addition. The food pathogens Salmonella spp. and Listeria monocytogenes were never detected. The dominance of the species inoculated was demonstrated by denaturing gradient gel electrophoresis (DGGE), whereas strain recognition was evaluated by randomly amplified polymorphic DNA (RAPD)-PCR. From the results obtained, $L$ b. paracase $\mathrm{NdP78}$ and $S$. macedonicus NdP1 were able to persist during the storage of Tosèla cheese and their combination influenced positively the sensory characteristics and shelf-life of the final product.
\end{abstract}

(c) 2010 Elsevier Ltd. All rights reserved.

\section{Introduction}

Due to the availability of nutrients in milk, fresh raw milk cheeses may host different pathogenic microorganisms (Donnelly, 2004). During production and ageing, starter lactic acid bacteria (SLAB) and non-starter lactic acid bacteria (NSLAB) grow in different stages (Settanni and Moschetti, 2010). The addition of salt, the environmental conditions, such as humidity and storage temperature, and the activity of SLAB and NSLAB may lower the risk of pathogen growth improving the safety of cheese products. The Commission Regulation EC 2073/2005 established the microbiological criteria for the control of the four main pathogens (Listeria monocytogenes,

\footnotetext{
* Corresponding author. Tel.: +390461 615117; fax: +390461 615288.

E-mail address: elena.franciosi@iasma.it (E. Franciosi).

1 Present address: Free University of Bolzano-Bozen, Faculty of Science and Technology, Piazza Università 1, 39100 Bolzano, Italy.
}

Staphylococcus aureus, Salmonella spp., and Escherichia coli) of cheese.

Tosèla is a traditional fresh cheese produced in the eastern part of Trentino region and its name, in the local dialect, derives from the shearing action of curdle once it is placed in the moulder. The curdle is soft and compact, its colour is white or light straw and its shape is cylindrical or parallelepiped. This cheese is consumed within a few days of manufacturing, after roasting. In the past, Tosèla was made from raw cows' milk but, to avoid hygienic implications, it is nowadays produced with pasteurised milk, despite the fact that cheeses made from raw milk are well known to have more intense flavours than cheeses of the same age and type made from pasteurised milk (Albenzio et al., 2001; Beuvier et al., 1997; Demarigny et al., 1997). The production technology of Tosèla cheese is quite simple: pasteurised milk is warmed to $35^{\circ} \mathrm{C}$ and calf rennet is added. No bacterial starter is inoculated, since it does not need a driven fermentation process and it is consumed soon after production. However, the shelf-life of this cheese, even if kept under refrigeration, does not exceed three days with the 
Table 1

Experimental cheeses made with NSLAB.

\begin{tabular}{|c|c|c|c|}
\hline Experimental cheeses & Bacterial inoculums & pH after curdle extraction & $\mathrm{pH}$ after $48 \mathrm{~h}$ \\
\hline $\mathrm{CC}$ & - & $6.63 \pm 0.0$ & $5.88 \pm 0.1$ \\
\hline $1-\mathrm{A}$ & Lb. paracasei NdP78 & $6.60 \pm 0.0$ & $5.55 \pm 0.1$ \\
\hline $1-B$ & Lb. paracasei NdP88 & $6.63 \pm 0.1$ & $5.77 \pm 0.2$ \\
\hline $1-\mathrm{C}$ & S. macedonicus NdP1 & $6.56 \pm 0.1$ & $5.58 \pm 0.1$ \\
\hline $1-\mathrm{D}$ & S. macedonicus PB14-1 & $6.61 \pm 0.1$ & $5.80 \pm 0.1$ \\
\hline $2-\mathrm{A}$ & Lb. paracasei NdP78 - Lb. paracasei NdP88 & $6.67 \pm 0.1$ & $5.52 \pm 0.2$ \\
\hline $2-\mathrm{B}$ & Lb. paracasei NdP78 - S. macedonicus NdP1 & $6.45 \pm 0.1$ & $5.41 \pm 0.1$ \\
\hline $2-C$ & Lb. paracasei NdP78 - S. macedonicus PB14-1 & $6.55 \pm 0.0$ & $5.58 \pm 0.1$ \\
\hline 2-D & Lb. paracasei NdP88 - S. macedonicus NdP1 & $6.56 \pm 0.1$ & $5.54 \pm 0.0$ \\
\hline $2-\mathrm{E}$ & Lb. paracasei NdP88 - S. macedonicus PB14-1 & $6.56 \pm 0.1$ & $5.60 \pm 0.2$ \\
\hline $2-\mathrm{F}$ & S. macedonicus NdP1 - S. macedonicus PB14-1 & $6.54 \pm 0.0$ & $5.55 \pm 0.1$ \\
\hline
\end{tabular}

consequent limited distribution of the product to a local level. The extension of the shelf-life would require the addition of chemical preservatives.

In recent years, consumers have became particularly cautious in the choice of foods and in particular they pay attention mainly to the presence of food additives. "Natural" and "traditional" foods, processed with no added chemicals, are becoming more and more attractive, especially those obtained with technologies that employ strategies of "biopreservation" (Settanni and Corsetti, 2008). This term refers to the extension of the shelf-life and improvement of the safety of foods using microorganisms and/or their metabolites (Ross et al., 2002).

In this regard, $L A B$ constitute the most interesting microbial group. The growth of LAB itself shows positive effects, since LAB produce lactic acid during sugar fermentation, that inhibits the majority of unwanted microorganisms (pathogenic and spoilage) due to the acidification of the environment (Atrih et al., 2001). Moreover, several LAB are able to secrete some metabolites with specific antagonistic activity and antibacterial effects such as antifungal compounds (Lavermicocca et al., 2000), bacteriocins and antibiotics (De Vuyst and Vandamme, 1994; Höltzel et al., 2000). Several LAB enjoy a "generally recognised as safe" (GRAS) status since they have been used to producing foods for millennia without safety problems (Bernardeau et al., 2008; Ogier et al., 2008; Casalta and Montel, 2008). Thus, these bacteria are food-grade and are commonly added during the manufacturing of fermented (Settanni et al., 2005), as well as non-fermented foods to preserve them and are well accepted by consumers (Settanni and Corsetti, 2008).

The main objective of the present study was to evaluate the suitability of six NSLAB strains to extend the shelf-life of the fresh cheese Tosèla. The strains were chosen among NSLAB previously isolated and identified at different stages of ripening of "Nostrano di Primiero", a typical cheese of Trentino region, in order to create a link between production and environment. The above two cheeses are made in the same dairy factory using the same milk bulk, from the same farmers, which is pasteurised only for Tosèla production. To our knowledge, this is the first report on the investigation of suitability of $S$. macedonicus strains to produce Italian cheeses.

\section{Materials and methods}

\subsection{Strains}

Six strains of NSLAB (Lactobacillus paracasei NdP78, NdP81 and NdP88, Lactobacillus rhamnosus NdP93, Streptococcus macedonicus NdP1 and PB14-1), previously isolated from "Nostrano di Primiero" cheese (Poznanski et al., 2004) were used in this study. Lactobacilli were grown in MRS (Oxoid) for $24 \mathrm{~h}$ at $30^{\circ} \mathrm{C}$, while streptococci in M17 (Oxoid) for $24 \mathrm{~h}$ at $37^{\circ} \mathrm{C}$.

\subsection{Kinetics of acidification and growth in milk medium}

In order to evaluate the acidifying capacity of each strain, overnight cultures were centrifuged at $5000 \times \mathrm{g}$ for $5 \mathrm{~min}$, washed with peptone water $(\mathrm{PW})(0.1 \%$ mycological peptone, Oxoid $)$ and resuspended in $10 \mathrm{~mL}$ skim milk (SkM, Oxoid). The incubation was carried out at the optimal growth temperature for 4 days. Measurements of $\mathrm{pH}$ were performed using a pH meter PT1000 (Knick, Berlin, Germany) equipped with a Hamilton electrode (Hamilton Bonaduz, Bonaduz, Switzerland), every $2 \mathrm{~h}$ in the first $8 \mathrm{~h}$ and then at 24, 48, 72 and $96 \mathrm{~h}$ after inoculation.

Growth curves were determined for the more acidifying strains. Inoculums were performed as above reported in $10 \mathrm{~mL}$ full-fat ultra-high-temperature (UHT) milk (Latte Trento Sca, Trento, Italy). Test tubes were incubated for 6 days during which plate counts were carried out after $0,2,6,24,48,120$ and $144 \mathrm{~h}$. Aliquots of $1 \mathrm{~mL}$ were collected from each tube and the colonies were counted in MRS and M17 agar for lactobacilli and streptococci, respectively. Colony counts occurred after $48 \mathrm{~h}$ at the optimal growth temperature for the different selected strains.

All experiments were carried out in duplicate, while measurements in triplicate.

\subsection{Assays for bacteriocin activity}

The antimicrobial activity of each strain was first detected by the agar-spot deferred method and the strains showing positive results were subsequently tested by the well diffusion assay (Schillinger and Lücke, 1989). Both assays were performed following the modifications of Corsetti et al. (2004) using Lactobacillus sakei LMG 2313, Listeria innocua 4202 and Listeria monocytogenes ATCC $19114^{\mathrm{T}}$ as indicator strains. Tests were carried out in triplicate.

Sensitivity of active supernatants to proteolytic enzymes was tested by treatment with proteinase $\mathrm{K}(12.5 \mathrm{U} / \mathrm{mg})$, protease $\mathrm{B}$ (45 U/mg) and trypsin $(10.6 \mathrm{U} / \mathrm{mg}$ ) at a final concentration of $1 \mathrm{mg} / \mathrm{mL}$ in phosphate buffer ( $\mathrm{pH}$ 7.0). The supernatants were incubated for $2 \mathrm{~h}$ at $37{ }^{\circ} \mathrm{C}$ and the remaining activity was determined by well diffusion assay (Settanni et al., 2005).

The antibacterial activity of the supernatants was evaluated by the "critical dilution assay" (Barefoot and Klaenhammer, 1983). Bacteriocin activity was defined as the reciprocal of the highest dilution showing definite inhibition of the indicator strains and was expressed as activity units per milliliter $(\mathrm{AU} / \mathrm{mL})$.

\subsection{Experimental pilot-scale cheese making}

Experimental cheese making trials (Table 1) were carried out in a dairy pilot plant (Fondazione Edmund Mach, San Michele all'Adige, Trento, Italy) using a Swiss-type vat. $L b$. paracasei NdP78 and NdP88 and S. macedonicus NdP1 and PB14-1 were tested in $50 \mathrm{~L}$ 


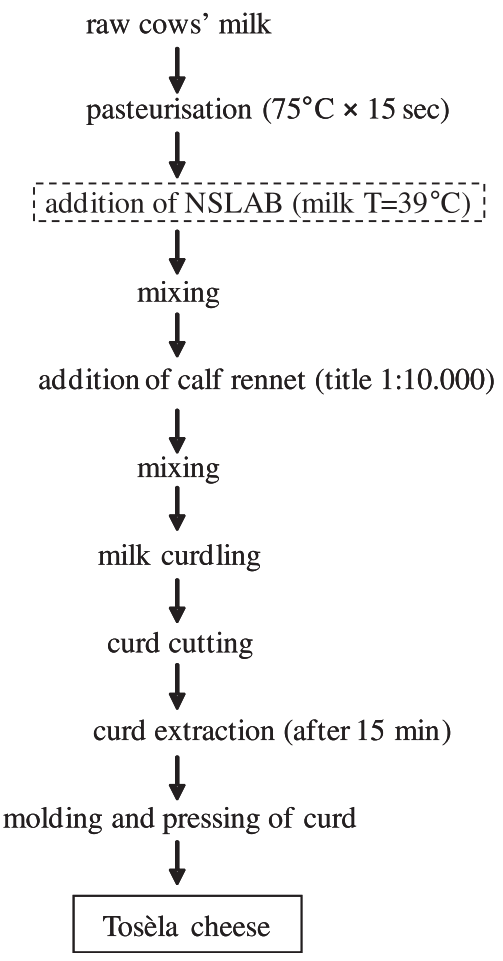

Fig. 1. Flow diagram of Tosèla cheese production. The step in sketched rectangle was performed for experimental cheese productions.

of pasteurised $\left(75^{\circ} \mathrm{C} \times 15 \mathrm{~s}\right)$ cows' milk singly (four inoculums) or in dual combinations (six mixed inoculums). Cells were prepared as above reported (paragraph 2.1). Cell suspensions were standardised. Each cell suspension, diluted 1:10 (v/v), had a $600 \mathrm{~nm}$ optical density (O.D.) of ca. 1.25 , which roughly corresponds to a concentration of $10^{9} \mathrm{cfu} / \mathrm{mL}$ (Corsetti et al., 2007). O.D. were measured by means of a biophotometer (Eppendorf AG, Hamburg, Germany). Before mixing, cell suspensions were further diluted to $10^{7} \mathrm{cfu} / \mathrm{mL}$ in order to obtain a final concentration of about $10^{4} \mathrm{cfu} / \mathrm{mL}$ in the vat skim milk. A control cheese was also produced without any bacterial addition. Cheese trials were carried out in duplicate and $\mathrm{pH}$ was measured after 4 and $48 \mathrm{~h}$ from curdle moulding.

\subsection{Sensory analysis}

A panel of six tasters trained in the sensory analysis of cheeses made in Trentino region, evaluated 48 h-refrigerated samples of Tosèla after roasting, which is the common way of consuming this kind of cheese. The control cheese produced without NSLAB addition was also evaluated. The tasters were asked to recognise specific sensory descriptors for taste (flat, sweet, acidic and bitter) and texture (creamy, soft, gum and hard), following the methodology reported by Franciosi et al. (2008).

\subsection{Evaluation of cheese shelf-life}

The shelf-life of the cheeses was evaluated after 7 days of refrigerated storage. A cheese from each cheese-making trial was sampled. Cheese samples of $25 \mathrm{~g}$ were homogenised ( $2 \mathrm{~min}$ at high speed) by means of a stomacher (Laboratory Blender Stomacher 400, Seward, London, UK) and serially diluted in PW (Franciosi et al., 2008). Decimal dilutions were used for the following microbial counts: total bacterial count (TBC) were counted on plate count agar (PCA) added with $1 \mathrm{~g} / \mathrm{L}$ SkM, incubated aerobically at $30{ }^{\circ} \mathrm{C}$ for $24 \mathrm{~h}$; coliforms on violet red bile agar (VRBA), incubated anaerobically for $24 \mathrm{~h}$ at $37{ }^{\circ} \mathrm{C}$; mesophilic rod LAB on MRS, incubated anaerobically for $48 \mathrm{~h}$ at $30^{\circ} \mathrm{C}$; thermophilic coccus LAB on M17, incubated anaerobically for $48 \mathrm{~h}$ at $45^{\circ} \mathrm{C}$; enterococci on kanamycin aesculin azide (KAA) agar, incubated aerobically for $24 \mathrm{~h}$ at $37^{\circ} \mathrm{C}$; positive coagulase staphylococci on Bair Parker (BP, Oxoid) added with R.P.F. supplement (Oxoid), incubated aerobically for $48 \mathrm{~h}$ at $37^{\circ} \mathrm{C}$. Microbiological counts were performed in duplicate.

Detection of Salmonella spp. and Listeria monocytogenes was carried out on $25 \mathrm{~g}$ of cheese sample, after pre-enrichment as described by Mucchetti et al. (2008).

\subsection{Experimental factory-scale cheese making}

Inoculums that generated cheeses with higher sensory scores were chosen to prepare fresh cultures to be added to the milk bulk to produce Tosèla cheese (Fig. 1) at factory-scale. These trials were carried out in the same dairy factory (Caseificio Sociale di Primiero, Primiero, Trento, Italy), located in the alpine province of Trento (northern Italy), where Nostrano di Primiero cheeses used for NSLAB isolation (Poznanski et al., 2004) were produced.

Raw cows' milk was maintained under mild stirring in a 8000-L polyvalent vat. One thousand liters of milk was pasteurised and transferred to the vat for cheese manufacturing. NSLAB were inoculated at a final concentration of about $10^{4} \mathrm{cfu} / \mathrm{mL}$. A control cheese, without NSLAB addition, was also produced. The trials were carried out in duplicate in 2 consecutive days.

\subsection{Persistence of selected NSLAB}

The presence of the cultures added in cheese was first verified at species level by the culture-independent technique PCR-denaturing gradient gel electrophoresis (DGGE). The DGGE samples were prepared by performing PCR amplification of the V3 region of the 16S rRNA gene according to Ercolini et al. (2001). Size and quantities of PCR products were determined in $2 \%(\mathrm{w} / \mathrm{v})$ agarose gel. DGGE analysis was carried out using the DC code Universal Mutation Detection System (Bio-Rad) on $16 \mathrm{~cm} \times 16 \mathrm{~cm} \times 1 \mathrm{~mm}$ gels. The PCR products $(8 \mu \mathrm{L})$ were loaded on gels with $8 \%(\mathrm{w} / \mathrm{v})$ acrylamide (acrylamide-bisacrylamide $37.5: 1$ ) and a $25-60 \%$ of urea and formamide gradient, increasing in the direction of electrophoresis. A 100\% denaturing solution consisted of $7 \mathrm{M}$ urea and $40 \%(\mathrm{v} / \mathrm{v})$ deionised formamide. Electrophoresis was conducted in $1 \times$ TAE [40 mM Tris, $20 \mathrm{mM}$ acetic acid, and 1 M EDTA (pH 8.0)] buffer at $150 \mathrm{~V}$ for $5 \mathrm{~h}$ at $60{ }^{\circ} \mathrm{C}$. After runs, gels were stained for $15 \mathrm{~min}$ in ethidium bromide solution, rinsed in distilled $\mathrm{H}_{2} \mathrm{O}$ for $20 \mathrm{~min}$, and photographed on a UV transilluminator table. Pure cultures were included in DGGE analysis as reference strains for species comparison.

Strains were recognised by a culture-dependent strategy consisting of randomly amplified polymorphic DNA-PCR (RAPD-PCR). Microbiological counts of experimental cheeses were carried out on M17 (incubated at $45^{\circ} \mathrm{C}$ for $48 \mathrm{~h}$ ) and MRS (incubated at $30^{\circ} \mathrm{C}$ for $48 \mathrm{~h}$ ) and at least 6 colonies were randomly collected from each countable plate. After colony and cell observation, DNA was extracted from the isolates by the Instagene Matrix kit (Bio-Rad, Hercules, CA), following the manufacturer instructions. $5 \mu \mathrm{L}$ cell extracts were used as template for PCR reactions. RAPD-PCR was carried out in a $25-\mu \mathrm{L}$ reaction mix using primers PC1 (Poznanski et al., 2004), AB111, and AB106 (Van den Braak et al., 2000). Amplifications were performed by means of PTC-100 Thermal Cycler (MJ Research Inc., Waltham, MA). The PCR products were separated by electrophoresis on $1.5 \%(\mathrm{w} / \mathrm{v})$ agarose gel (Gibco BRL, Cergy Pontoise, France) and visualised by UV transillumination 


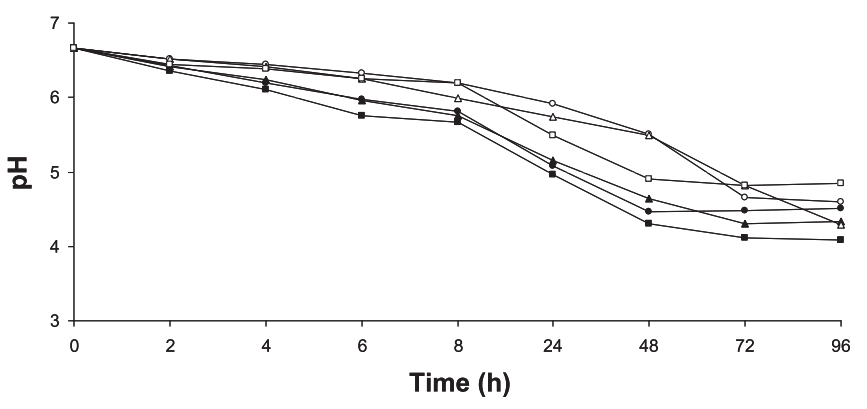

Fig. 2. Acidifying capacity of NSLAB. Symbols: $\mathbf{\square}$, Lb. paracasei NdP78; $\boldsymbol{\Lambda}$, Lb. paracase NdP88; O, Lb. paracasei NdP81; $\Delta$, Lb. rhamnosus NdP93; • S. macedonicus NdP1; $\square$, S. macedonicus PB14-1

after staining with ethidium bromide $(0.5 \mu \mathrm{g} / \mathrm{mL})$. Deoxyribonucleic acid ladder $1 \mathrm{~Kb}$ (Invitrogen, Carlsbad, CA) was used as a molecular size marker.

\section{Results}

\subsection{Kinetics of acidification and growth of NSLAB in milk media}

Six NSLAB strains were characterised for their acidifying capacity in skim milk (Fig. 2) in order to test their suitability to perform this study. Strains $L b$. paracasei NdP81 and $L b$. rhamnosus NdP93 showed a very limited ability to acidify milk medium ( $\mathrm{pH}>5.6$ after $48 \mathrm{~h}$ ), therefore they were not further considered. The two strains $L b$. paracasei NdP78 and S. macedonicus NdP1 showed a stronger acidifying ability; after $24 \mathrm{~h}$, they lowered the skim milk pH to 5.0 .

Growth curves of $L b$. paracasei NdP78 and NdP88 and S. macedonicus NdP1 and PB14-1 are shown in Fig. 3. In terms of growth rate, $L b$. paracasei NdP78 and S. macedonicus NdP1 were the best strains among lactobacilli and streptococci, respectively. They grew more than $2 \log$ cycles in 6 h. S. macedonicus PB14-1 grew very slowly, reaching a cell concentration of about $10^{5} \mathrm{CFU} / \mathrm{mL}$ after $8 \mathrm{~h}$.

\subsection{Evaluation of antimicrobial compound production}

The four NSLAB chosen for their growth capacity in milk were initially tested for antibacterial compound production by means of the agar-spot deferred method against three indicator strains with high sensitivity to bacteriocins (Hartnett et al., 2002; Corsetti et al.,

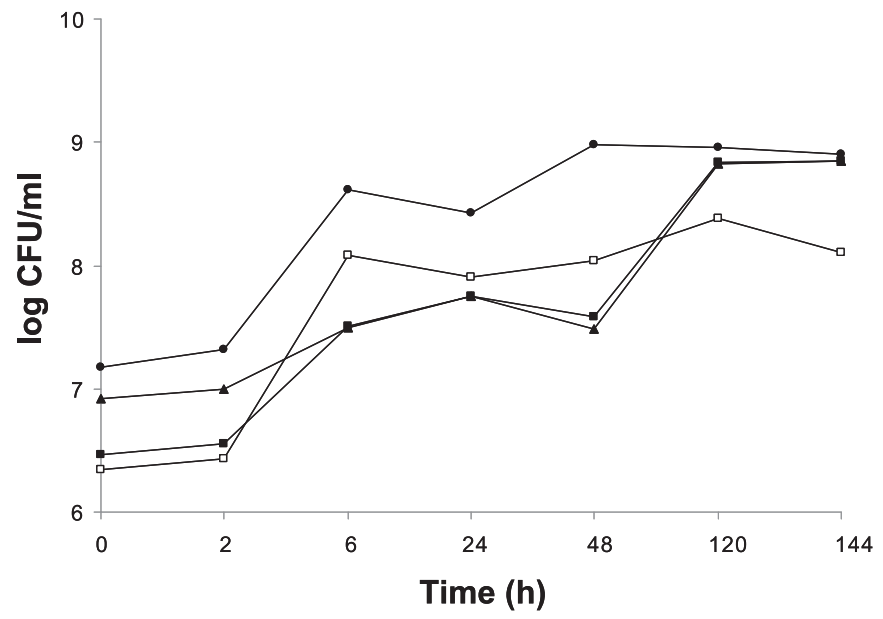

Fig. 3. Growth curves of NSLAB. Symbols: $\mathbf{\square}, L b$. paracasei NdP78; $\mathbf{A}, L$ b. paracasei NdP88; • S. macedonicus NdP1; $\square$, S. macedonicus PB14-1.
Table 2

Critical sensory attributes evaluated in control and experimental Tosèla cheeses.

\begin{tabular}{lllllllll}
\hline \multirow{2}{*}{ Cheeses } & \multicolumn{9}{l}{ Sensory descriptors } \\
\cline { 2 - 9 } & Flat & Sweet & Acidic & Bitter & Creamy & Soft & Gum & Hard \\
\hline CC & \pm & + & - & - & - & + & \pm & - \\
$1-A$ & + & \pm & - & - & - & + & \pm & - \\
$1-B$ & + & \pm & - & - & - & + & \pm & - \\
$1-C$ & + & \pm & - & - & - & + & \pm & - \\
$1-D$ & + & \pm & - & - & - & + & \pm & - \\
$2-A$ & \pm & + & - & - & - & + & \pm & - \\
$2-B$ & - & ++ & - & - & - & ++ & \pm & - \\
$2-C$ & \pm & + & - & - & - & + & \pm & - \\
$2-D$ & \pm & + & - & - & - & + & \pm & - \\
$2-E$ & \pm & + & - & \pm & - & - & ++ & \pm \\
$2-F$ & \pm & + & - & - & - & + & \pm & - \\
\hline
\end{tabular}

Symbols: - , not recognised; \pm , weak; + , moderate; ++ , strong. CC, control cheese The results shown are referred to the majority of assessors.

2008). In this step, the possible inhibitory effect of the organic acids and of hydrogen peroxide was not excluded. Only one strain (Lb. paracasei NdP78) produced an inhibition zone against L. innocua 4202 and L. monocytogenes ATCC $19114^{\mathrm{T}}$. Subsequently, the active supernatant was treated with catalase, neutralised, sterilised by filtration through a $0.22 \mu \mathrm{m}$ pore size filter (Nucleopore, Costar Corporation, Cambridge, MA, USA) and tested by the well diffusion assay against the same two indicators. The supernatant kept the antimicrobial activity showing a measurable clear zone around the well $(1.53 \pm 0.06 \mathrm{~cm}$ vs L. innocua 4202 and $1.73 \pm 0.15 \mathrm{~cm}$ L. monocytogenes ATCC $19114^{\mathrm{T}}$ ). The inhibitory activity, quantified by the critical dilution assay, was $640 \mathrm{AU} / \mathrm{mL}$ against L. monocytogenes ATCC $19114^{\mathrm{T}}$.

The inhibitory activity of $L b$. paracasei NdP78 was also tested against the other NSLAB used in cheese making trials ( $L b$. paracasei NdP88, S. macedonicus NdP1 and PB14-1). None of the NSLAB strains were inhibited by the active supernatant of strain NdP78.

The antibacterial compound was inactivated by proteolytic enzymes, proving its proteinaceous nature, a general characteristic of bacteriocins (Tagg et al., 1976; Jack et al., 1995). This substance has not yet been characterised for amino acid and gene sequences, therefore it will be referred to as bacteriocin-like inhibitory substance (BLIS).

\subsection{Experimental cheese making and selection of NSLAB}

Ten experimental cheeses (Table 1) were produced at pilot-scale cheese-making with individual and dual NSLAB combination inoculums. A control cheese, without NSLAB addition was also manufactured. Milk used for cheese making hosted approximately 3.6 $\log \mathrm{CFU} / \mathrm{mL}$ total bacterial counts (results not shown). The values of $\mathrm{pH}$ measured after curdling and then at the time of sensory evaluation (Table 1 ) showed that cheese $2-B$ was characterised by the highest acidity.

The results of the sensory evaluation are shown in Table 2 . The panellists found the four cheeses inoculated with single NSLAB as having a "flat" taste. Regarding the dual combinations of NSLAB, the six tasters agreed that cheese $2-\mathrm{B}$, produced with the mixed inoculums $L b$. paracasei NdP78 - S. macedonicus NdP1, showed the best flavour intensity and texture consistence as being characterised by a sought moderate acidic taste and a soft structure.

Cheese 2-B, as well as CC, were produced once again in order to investigate their shelf-life. Several microbial groups were counted in milk bulks, before rennet addition, and cheeses, after seven days of conservation under refrigerated storage (Fig. 4). The cheeses were not roasted before microbial counts. As expected, the addition of the mixed strain preparation in milk had an impact on the total microbial count (from $3.66 \log \mathrm{CFU} / \mathrm{mL}$ for milk without NSLAB to 


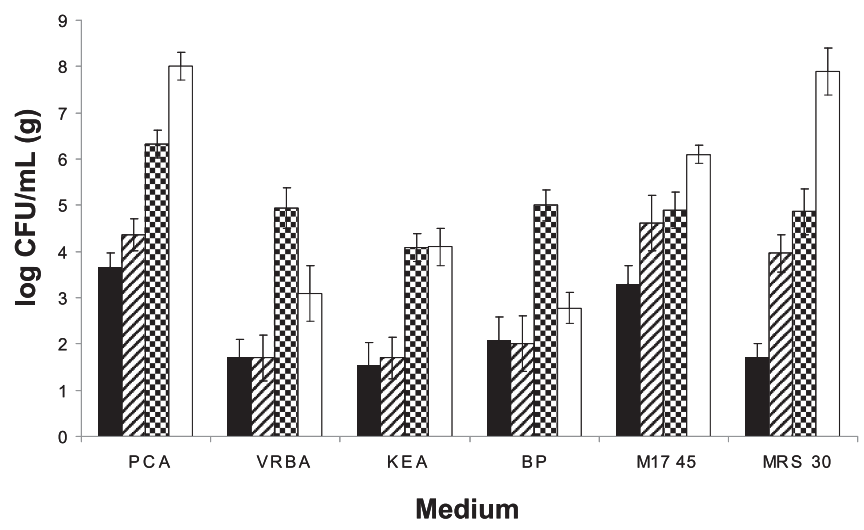

Fig. 4. Microbial counts of milk and cheese sample. Symbols: black columns, milk without NSLAB addition; striped columns, milk added with $L b$. paracasei NdP78 and S. macedonicus NdP1; chequered columns, control cheese; white columns, cheese 2-B.

4.36 log CFU/mL for milk added with NSLAB) and LAB concentrations: thermophilic cocci and mesophilic rods reached 4.62 and $3.96 \log \mathrm{CFU} / \mathrm{mL}$, respectively, in milk added with $\mathrm{Lb}$. paracasei NdP78 - S. macedonicus NdP1. After 1-week storage, CC showed higher concentrations of coliforms (4.93 log CFU/g) and staphylococci (5.00 log CFU/g) than 2-B cheese (3.10 and $2.78 \log \mathrm{CFU} / \mathrm{g}$, respectively). The presence of coliforms, as well as staphylococci, in pasteurised milk may be attributed to a post-treatment contamination by the dairy equipment and environment. NSLAB counts showed an opposite trend, since they were found to be higher in 2$\mathrm{B}$ cheese. Thermophilic cocci grew but their increase was about 2 log cycle lower than the mesophilic rods which reached a final concentration of $7.90 \log \mathrm{CFU} / \mathrm{g}$. The addition of the mixed culture Lb. paracasei NdP78 - S. macedonicus NdP1 was effective in controlling the development of the undesired bacterial groups (coliforms and staphylococci). Salmonella spp. and L. monocytogenes were absent in both cheeses.

\subsection{Industrial cheeses and fate of added strains}

After the above results, $L b$. paracasei NdP78 and S. macedonicus NdP1 were chosen to be used as a dual strain culture to produce Tosèla cheese at the industrial level.

In order to verify the persistence of the NSLAB species added, DGGE analysis was performed on cheeses (Fig. 5). CC, just after production, did not show the DNA bands belonging to $\mathrm{Lb}$. paracasei and/or S. macedonicus species, but a weak band (L2-S2) that could belong to both species was detected after 7 days. On the contrary, both $\mathrm{Lb}$. paracasei and S. macedonicus could be clearly detected until the seventh day of storage in 2-B cheese.

Since DGGE results from CC revealed the presumptive presence of $\mathrm{Lb}$. paracasei - S. macedonicus, the persistence of the added strains was checked in the 7-day old 2-B Tosèla cheese, and their absence in CC was verified. The colonies collected after microbiological counts were analysed by RAPD-PCR (Fig. 6). CC showed a high heterogeneity of DNA band profile of the isolates (Fig. 6A), whereas cheese $2-B$ clearly showed the persistence of $L b$. paracasei NdP78 and S. macedonicus NdP1 (Fig. 6B), since all colonies picked up from agar plate were characterised by the same RAPD patterns of the pure strains, highlighting their dominance.

\section{Discussion}

In order to set up a pool of strains to be used as a mixed inoculum for Toséla cheese production, the performances of six NSLAB strains (Lb. paracasei NdP78, NdP81 and NdP88, Lb. rhamnosus

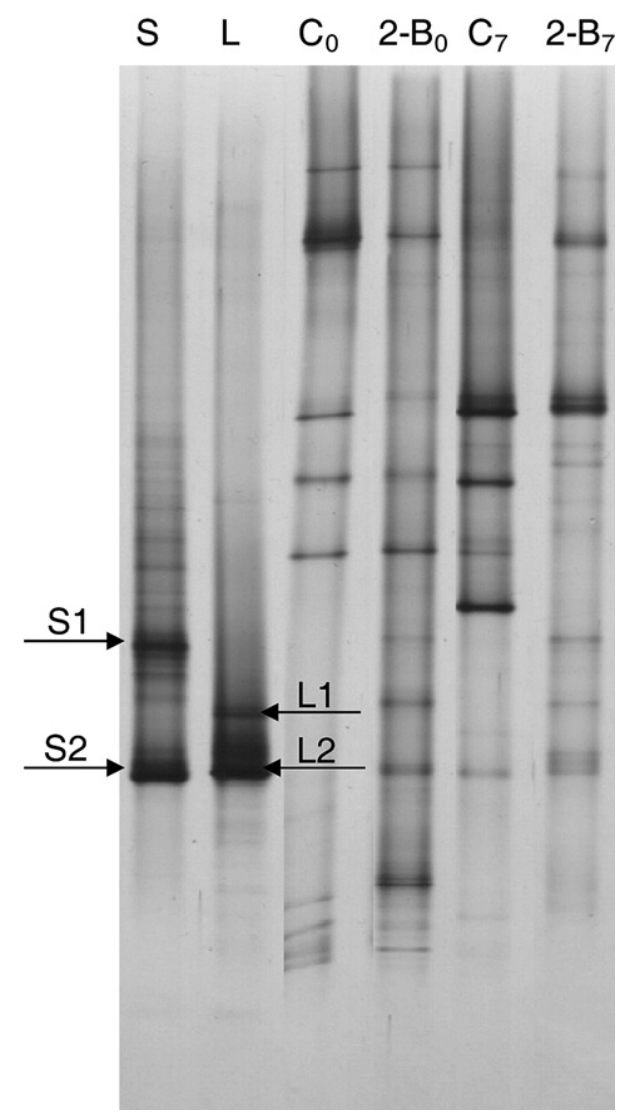

Fig. 5. DGGE profiles of $16 \mathrm{~S}$ rRNA gene V3 regions obtained from cheeses. Lanes: S, UHT milk added with $S$. macedonicus NdP1; S, UHT milk added with $L$ b. paracasei NdP78; $C_{0}$, control cheese at time zero; $2-B_{0}$, cheese 2-B at time zero; $C_{7}$, control cheese after seven days; $2-B_{7}$, cheese $2-B$ after seven days.

NdP93, S. macedonicus NdP1 and PB14-1) were investigated. Typical SLAB species were not included in this study, because their strong acidifying ability could cause a curdle over-acidification, causing a decrement of the quality of the final product. In order to create a link with the production environment, the strains were chosen among those previously isolated and identified form Nostrano di Primiero cheese (Poznanski et al., 2004), a typical cheese of Trentino region produced in the same dairy factory.

Since the species $S$. macedonicus is generally reported to be a moderately acidifying NSLAB (De Vuyst and Tsakalidou, 2008), two strains belonging to this species (NdP1 and PB14-1) were tested together with strains belonging to other NSLAB species: $L b$. paracasei and Lb. rhamnosus (Chamba and Irlinger, 2004). S. macedonicus is a thermophilic, homofermentative NSLAB belonging to the $S$. bovis/S. equinus complex (De Vuyst and Tsakalidou, 2008). The first isolation of this species was during a survey of the LAB microbiota of naturally fermented Greek Kasseri cheese (Tsakalidou et al., 1994) and it has been also detected in several Italian raw milk samples (Franciosi et al., 2009a) and raw milk cheese products (Mora et al., 2003; Pacini et al., 2006; Lombardi et al., 2004; Poznanski et al., 2004). The characterisation of S. macedonicus (Anastasiou et al., 2007) demonstrated its food-grade and nonpathogenic status. De Vuyst and Tsakalidou (2008) speculated on its suitability as adjunct culture for dairy fermentations. Furthermore, due to in situ bacteriocin production in milk, some strains of S. macedonicus showed a high potentiality as protective cultures in dairy products (Van den Berghe et al., 2006). So far, cheese trials using S. macedonicus have only been performed for Kasseri cheese production (Anastasiou et al., 2007). 

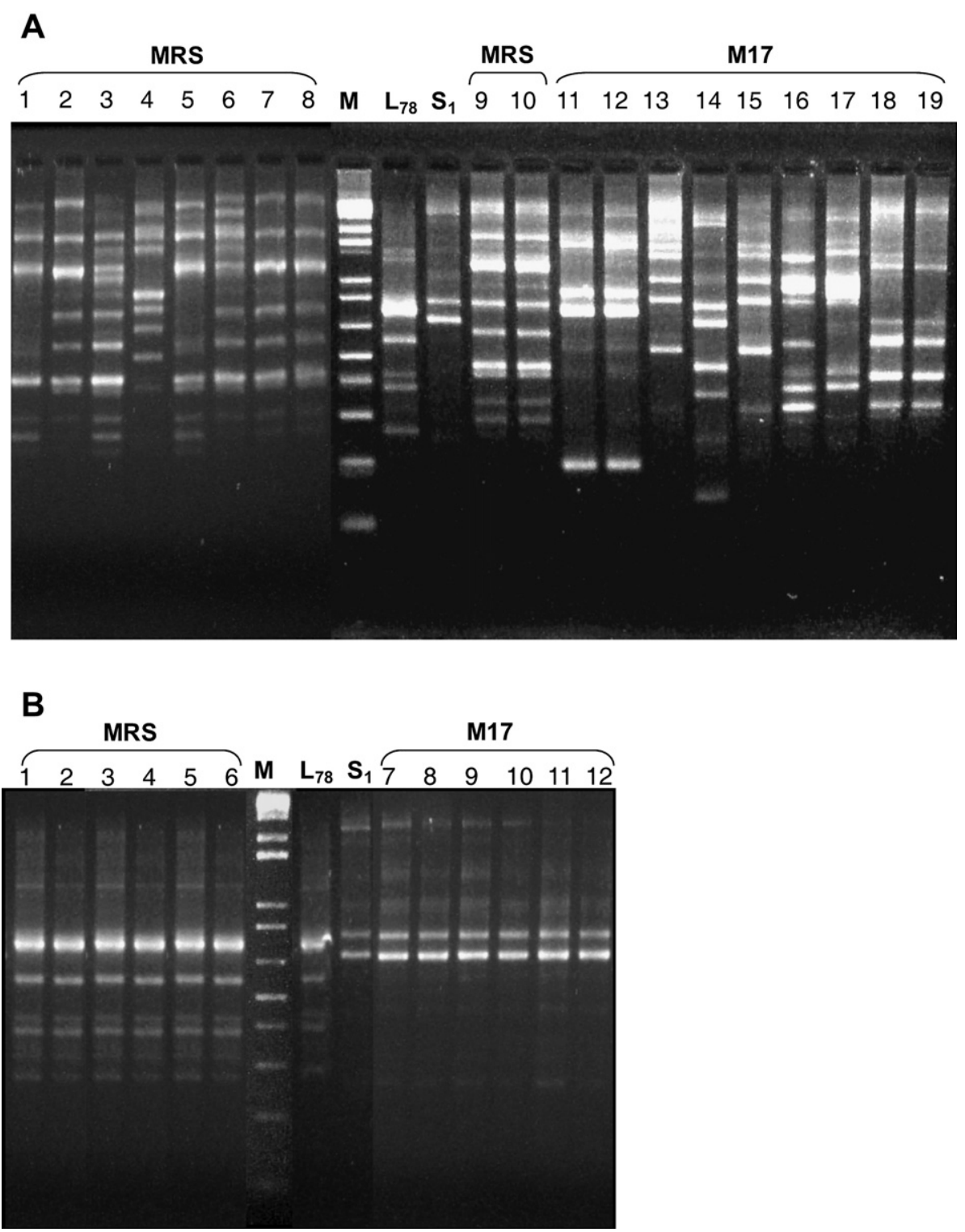

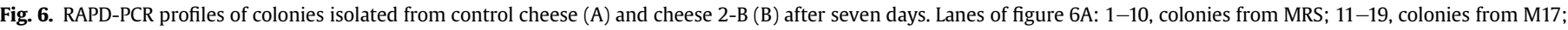

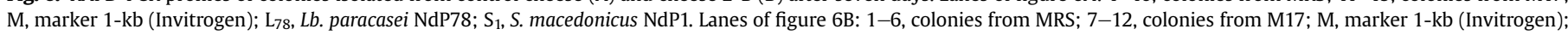
$\mathrm{L}_{78}$, Lb. paracasei NdP78; $\mathrm{S}_{1}, \mathrm{~S}$. macedonicus NdP1.

Two strains ( $L b$. paracasei NdP81 and Lb. rhamnosus NdP93) showed too low acidifying capacity, thus they were excluded from further characterisation. The four remaining NSLAB strains were investigated for their growth ability in milk and antimicrobial compound production. $L$ b. paracasei NdP78 was found to be a BLIS producer. Several $L b$. paracasei strains of cheese environment origin have been reported to produce bacteriocins with different spectra of action (Lozo et al., 2007; Ortu et al., 2007) and their use for biopreservation of cheese is of current interest (Buriti et al., 2007). Bacteriocin production may confer a competitive advantage and the success of a strategy based on in situ bacteriocin production depends on the persistence of the producer strains (Settanni et al., 2005). Franciosi et al. (2009b) found bacteriocin producing E. faecalis strains to persist longer than other E. faecalis strains during ripening of Puzzone di Moena cheese.

Interestingly, BLIS NdP78 selected in this work was active against $L$. monocytogenes. The use of NSLAB with anti-Listeria bacteriocin production as food bio-preservatives is well accepted (Settanni and Corsetti, 2008). Due to its anti-Listeria activity, BLIS
NdP78 may be preliminarily considered as bacteriocin of class II, according to the classification of Nes et al. (1996).

NSLAB were then used, singly or in pairs to produce experimental Tosèla cheeses at pilot-scale level. This production better mimics the conditions of cheese manufacturing in dairy factories than laboratory-scale experiments do. Hence, the evaluation of tasters may be better predictive and more reliable for the productions obtained at factory-scale. All eight panellists agreed in finding the ten experimental cheeses different from one another, and the overall preference was towards cheese 2-B produced with the mixed strain culture $L b$. paracasei NdP78 - S. macedonicus NdP1.

In order to improve the shelf-life, the above NSLAB combination was used to produce Toséla cheese at factory-scale level by pasteurised milk. After 7-days storage, the cheese processed with NSLAB addition showed lower concentration of potential spoilage and/or pathogenic microbial groups (coliforms and coagulase positive staphylococci). Neither Salmonella spp. nor L. monocytogenes were found. In accordance with EC 2073/2005, the absence of both human pathogenic microorganisms is required for 
raw milk cheese consumption. Moreover, Toséla cheese is only consumed after roasting at high temperatures (i.e. cooking), which are effective in reducing the risk associated with living foodborne pathogens.

The dominance of the added strains $L b$. paracasei NdP78 and S. macedonicus NdP1 was checked firstly at species level by DGGE analysis. DGGE is routinely applied to monitor, detect and identify microorganisms in complex food matrices (Settanni et al., 2006), but it cannot provide information at strain level. Thus, the persistence of the selected NSLAB strains needs to be carried out with a culture-dependent typing tool (Corsetti et al., 2003). Strain recognition was then carried out by RAPD-PCR on DNA extracted from several colonies (Giraffa and Rossetti, 2004). Lb. paracasei NdP78 was easily detected in MRS while S. macedonicus NdP1, even if growing better in M17, was also able to develop colonies in MRS.

Different conclusions were drafted by this work. $L b$. paracasei NdP78 and S. macedonicus NdP1 were able to persist during production and refrigerated storage of Tosèla cheese, without causing an over-acidification of the product within seven days. The combined inoculums of these two NSLAB strains influenced positively the sensory characteristics of the final cheese, since it was well appreciated by expert tasters. Furthermore, the addition of the mixed culture $L b$. paracasei NdP78 - S. macedonicus NdP1 extended the shelf-life of Tosèla cheese, in terms of limitation of the development of coliforms and staphylococci and showing, for $L b$. paracasei NdP78, anti-Listeria ability. The addition of the dual strain culture $L b$. paracasei NdP78 - S. macedonicus NdP1 is suggested to produce Tosèla cheese with an extended shelf-life, this could possibly allow its distribution at longer distances from the production factory.

\section{Acknowledgements}

This study was financed by the dairy factory "Caseificio sociale di Primiero" (Mezzano, TN, Italy). Author Luca Settanni is grateful to Prof. Douwe van Sinderen (Alimentary Pharmabiotic Centre and Department of Microbiology, National University of Ireland, Cork, Ireland) for kindly providing L. innocua 4202 and $\mathrm{Lb}$. sakei LMG 2313 used in antagonism tests.

\section{References}

Albenzio, M., Corbo, M.R., Rehman, S.U., Fox, P.F., De Angelis, M., Corsetti, A., Gobbetti, M., 2001. Microbiological and biochemical characteristics of Canestrato Pugliese cheese made from raw milk, pasteurized milk, or by heating the curd in hot whey. Int. J. Food Microbiol. 67, 35-48.

Anastasiou, R., Georgalaki, M., Manolopoulou, E., Kandarakis, I., De Vuyst, L., Tsakalidou, E., 2007. The performance of Streptococcus macedonicus ACA-DC 198 as starter culture in Kasseri cheese production. Int. Dairy J. 17, 208-217.

Atrih, A., Rekhif, N., Moir, A.J.G., Lebrihi, A., Lefebvre, G., 2001. Mode of action, purification and amino acid sequence of plantaricin C19, an anti-Listeria bacteriocin produced by Lactobacillus plantarum C19. Int. J. Food Microbiol. 68, 93-104.

Barefoot, S.F., Klaenhammer, T.R., 1983. Detection and activity of lactacin B, a bacteriocin produced by Lactobacillus acidophilus. Appl. Environ. Microbiol. 45, 1808-1815.

Bernardeau, M., Vernoux, J.P., Henri-Dubernet, S., Guéguen, M., 2008. Safety assessment of dairy microorganisms: the Lactobacillus genus. Int. J. Food Microbiol. 126, 278-285.

Beuvier, E., Berthaud, K., Cegarra, S., Dasen, A., Pochet, S., Buchin, S., Buboz, G., 1997 Ripening and quality of Swiss-type cheese made from raw, pasturized or microfiltered milk. Int. Dairy J. 7, 311-323.

Buriti, F.C.A., Cardarelli, H.R., Saad, S.M.I., 2007. Biopreservation by Lactobacillus paracasei in coculture with Streptococcus thermophilus in potentially probiotic and synbiotic fresh cream cheeses. J. Food Prot. 70, 228-235.

Casalta, E., Montel, M.-C., 2008. Safety assessment of dairy microorganisms: the Lactococcus genus. Int. J. Food Microbiol. 126, 271-273.

Chamba, J.-F., Irlinger, F., 2004. Secondary and adjunct cultures. In: Fox, P.F., McSweeney, P.L.H., Cogan, T.M., Guinee, T.P. (Eds.), Cheese: Chemistry, Physics and Microbiology. Elsevier, London, UK, pp. 191-206.

Commission Regulation EC, 2073/2005. Official Journal of the European Union Microbiological criteria for foodstuff.
Corsetti, A., Settanni, L., Braga, T.M., de Fatima Silva Lopes, M., Suzzi, G., 2008. An investigation on the bacteriocinogenic potential of lactic acid bacteria associated with wheat (Triticum durum) kernels and non-conventional flours. LWT Food Sci. Technol 41, 1173-1182.

Corsetti, A., Settanni, L., Van Sinderen, D., 2004. Characterization of bacteriocin-like inhibitory substances (BLIS) from sourdough lactic acid bacteria and evaluation of their in vitro and in situ activity. J. Appl. Microbiol. 96, 521-534.

Corsetti, A., Settanni, L., Valmorri, S., Mastrangelo, M., Suzzi, G., 2007. Identification of subdominant sourdough lactic acid bacteria and their evolution during laboratory-scale fermentations. Food Microbiol. 24, 592-600.

Corsetti, A., De Angelis, M., Dellaglio, F., Paparella, A., Settanni, L., Gobbetti, M., 2003. Characterization of sourdough lactic acid bacteria based on genotypic and cell wall protein analyses. J. Appl. Microbiol. 94, 641-654.

Demarigny, Y., Beuvier, E., Buchin, S., Pochet, S., Grappin, R., 1997. Influence of raw milk microflora on the characteristics of Swiss-type cheeses: II. Biochemical and sensory characteristics. Lait 77, 151-167.

De Vuyst, L., Tsakalidou, E., 2008. Streptococcus macedonicus, a multi-functional and promising species for dairy fermentations. Int. Dairy J. 18, 476-485.

De Vuyst, L., Vandamme, E.J., 1994. Bacteriocins of Lactic Acid Bacteria: Microbiology, Genetics and Applications. Blackie Academic and Professional, London.

Donnelly, C.W., 2004. Growth and survival of microbial pathogens in cheese. In: Fox, P.F., McSweeney, P.L.H., Cogan, T.M., Guinee, T.P. (Eds.), Cheese: Chemistry, Physics and Microbiology. Elsevier, London, UK, pp. 541-559.

Ercolini, D., Moschetti, G., Blaiotta, G., Coppola, S., 2001. Behavior of variable V3 region from $16 \mathrm{~S}$ rDNA of lactic acid bacteria in denaturing gradient gel electrophoresis. Curr. Microbiol. 42, 199-202.

Franciosi, E., Settanni, L., Carlin, S., Cavazza, A., Poznanski, E., 2008. A factory-scale application of secondary adjunct cultures selected from lactic acid bacteria during "Puzzone di Moena" cheese ripening. J. Dairy Sci. 91, 2981-2991.

Franciosi, E., Settanni, L., Cavazza, A., Poznanski, E., 2009a. Biodiversity and technological potential of wild lactic acid bacteria from raw cows' milk. Int. Dairy J. 19, 3-11.

Franciosi, E., Settanni, L., Cavazza, A., Poznanski, E., 2009b. Presence of enterococci in raw cow's milk and "Puzzone di Moena" cheese. J. Food Process. Preserv. 33, 204-217.

Giraffa, G., Rossetti, L., 2004. Monitoring of the bacterial composition of dairy starter cultures by RAPD-PCR. FEMS Microbiol. Lett. 237, 133-138.

Hartnett, D.J., Vaughan, A., Van Sinderen, D., 2002. Antimicrobial producine lactic acid bacteria isolated from raw barley and sorghum. J. Inst. Brewing 108, 169-177.

Höltzel, A., Gänzle, M.G., Nicholson, G.J., Hammes, W.P., Jung, G., 2000. The first lowmolecular-weight antibiotic from lactic acid bacteria: reutericyclin, a new tetrameric acid. Angew. Chem. Int. Ed. 39, 2766-2768.

Jack, R.W., Tagg, J.R., Ray, B., 1995. Bacteriocins of Gram-positive bacteria. Microbiol. Rev. 59, 171-200.

Lavermicocca, P., Valerio, F., Evidente, A., Lazzaroni, S., Corsetti, A., Gobbetti, M., 2000. Purification and characterization of novel antifungal compounds by sourdough Lactobacillus plantarum 21B. Appl. Environ. Microbiol. 66, 4084-4090.

Lombardi, A., Gatti, M., Rizzotti, L., Torriani, S., Andrighetto, C., Giraffa, G., 2004. Characterization of Streptococcus macedonicus strains isolated from artisanal Italian raw milk cheeses. Int. Dairy J. 14, 967-976.

Lozo, J., Jovcic, B., Kojic, M., Dalgalarrondo, M., Chobert, J.-M., Haertle, T., Topisirovic, L., 2007. Molecular characterization of a novel bacteriocin and an unusually large aggregation factor of Lactobacillus paracasei subsp paracasei BGSJ2-8, a natural isolate from homemade cheese. Curr. Microbiol. 55, $266-271$.

Mora, D., Ricci, G., Guglielmetti, S., Daffonchio, D., Fortina, M.G., 2003. 16S-23S rRNA intergenic spacer region sequence variation in Streptococcus thermophilus and related dairy streptococci and development of a multiplex ITS-SSCP analysis for their identification. Microbiology 149, 807-813.

Mucchetti, G., Bonvini, B., Remagni, M.C., Ghiglietti, R., Locci, F., Barzaghi, S. Francolino, S., Perrone, A., Rubiloni, A., Campo, P., Gatti, M., Carminati, D., 2008. Influence of cheese-making technology on composition and microbiological characteristics of Vastedda cheese. Food Control 19, 119-125.

Nes, I.F., Diep, D.B., Havårstein, L.S., Brurberg, M.B., Eijsink, V., Holo, H., 1996. Biosynthesis of bacteriocins in lactic acid bacteria. In: Venema, G., Huisin'tveld, J.H.J., Hugenholtz, J. (Eds.), Lactic Acid Bacteria: Genetics, Metabolism and Applications. Kluwer Academic Publishers, The Netherlands, pp. 17-32.

Ogier, J.-C., Casalta, E., Farrokh, C., Saïhi, A., 2008. Safety assessment of dairy microorganisms: the Leuconostoc genus. Int. J. Food Microbiol. 126, 286-290.

Ortu, S., Felis, G.E., Marzotto, M., Deriu, A., Molicotti, P., Sechi, L.A., Dellaglio, F., Zanetti, S., 2007. Identification and functional characterization of Lactobacillus strains isolated from milk and Gioddu, a traditional Sardinian fermented milk. Int. Dairy J. 17, 1312-1320.

Pacini, F., Cariolato, D., Andrighetto, C., Lombardi, A., 2006. Occurrence of Streptococcus macedonicus in Italian cheeses. FEMS Microbiol. Lett. 261, 69-73.

Poznanski, E., Cavazza, A., Cappa, F., Cocconcelli, P.S., 2004. Alpine environment microbiota influences the bacterial development in traditional raw milk cheese. Int. J. Food Microbiol. 92, 141-151.

Ross, R.P., Morgan, S., Hill, C., 2002. Preservation and fermentation: past, present and future. Int. J. Food Microbiol. 79, 3-16.

Schillinger, U., Lücke, F.K., 1989. Antibacterial activity of Lactobacillus sake isolated from meat. Appl. Environ. Microbiol. 55, 1901-1906. 
Settanni, L., Corsetti, A., 2008. Application of bacteriocins in vegetable food biopreservation. Int. J. Food Microbiol. 121, 123-138.

Settanni, L., Massitti, O., Van Sinderen, D., Corsetti, A., 2005. In situ activity of a bacteriocin-producing Lactococcus lactis strain. Influence on the interactions between lactic acid bacteria during sourdough fermentation. J. Appl. Microbiol. 99, 670-681.

Settanni, L., Moschetti, G., 2010. Non starter lactic acid bacteria used to improve cheese quality and provide health benefits. Food Microbiol. 27, 691-697.

Settanni, L., Valmorri, S., Van Sinderen, D., Suzzi, G., Paparella, A., Corsetti, A., 2006. Combination of multiplex PCR and PCR-DGGE for monitoring common sourdough-associated Lactobacillus species. Appl. Environ. Microbiol. 72, 3793-3796.

Tagg, J.R., Dajani, A.S., Wannamaker, L.W., 1976. Bacteriocins of Gram-positive bacteria. Bacteriol. Rev. 40, 722-756.
Tsakalidou, E., Manolopoulou, E., Kabaraki, E., Zoidou, E., Pot, B., Kersters, K. Kalantzopoulos, G., 1994. The combined use of whole-cell protein extracts for the identification (SDS-PAGE) and enzyme activity screening of lactic acid bacteria isolated from traditional Greek dairy products. Syst. Appl. Microbiol. 17 444-458.

Van den Berghe, E., Skourtas, G., Tsakalidou, E., De Vuyst, L., 2006. Streptococcus macedonicus ACA-DC 198 produces the lantibiotic, macedocin, at temperature and $\mathrm{pH}$ conditions that prevail during cheese manufacture. Int. J. Food Microbiol. 107, 138-147.

Van den Braak, N., Power, E., Anthony, R., Endtz, H., Verbrugh, H.A., Van Belkum, A 2000. Random amplification of polymorphic DNA versus pulsed field gel electrophoresis of SmaI DNA macrorestriction fragments for typing strains of vancomycin-resistant enterococci. FEMS Microbiol. Lett. 192, 45-52. 